\title{
Characterization and Assessment of Genetic Diversity for Agro- Morphological Traits of Ethiopian Chickpea (Cicer arietinum L.) Landraces
}

\author{
Awol Mohammed ${ }^{1, *}$, Bulti Tesso ${ }^{1}$ \\ ${ }^{1}$ Sirinka Agricultural Research Centre, Ethiopia. *Corresponding author. \\ 74, Woldia, Ethiopia (C) mawol50@yahoo.com (6) +251921958373
}

\begin{abstract}
This experiment was conducted in 2016 at Sirinka and Jari, under rain fed conditions to characterize and assess genetic diversity among the Ethiopian chickpea landraces. Two hundred two new germplasm accessions were grown in an alpha lattice design with three replications. Data on 16 traits were collected and analysed. Differences among the accessions were significant $(\mathrm{P}<0.01)$. The genotypes were grouped into five clusters with different sizes. The genetic distances among the clusters were significant. The highest diversity indices pooled over characters within zones were recorded for accessions from South West Shewa $(\mathrm{H}=2.03 \pm$ $0.05)$ followed by Gurage $(\mathrm{H}=0.81 \pm 0.08)$, West Shewa $(\mathrm{H}=0.73 \pm 0.04)$ and North Gonder $(\mathrm{H}=0.72 \pm 0.05)$. The existence of wider morpho-agronomic diversity among the chickpea collections implies the potential to improve the crop and the need to conserve the diversity. Future collecting operations of chickpea accessions should strategically focus on areas with relatively large variation. From a genetic conservation point of view, it appears that South West Shewa, Gurage, West Shewa and North Gonder could be suitable as in situ conservation sites.
\end{abstract}

Keywords: accessions, diversity, clustering.

\section{INTRODUCTION}

Chickpea (Cicer arietinum L.) is a selfpollinated diploid $(2 \mathrm{n}=2 \mathrm{X}=16)$, annual leguminous plant in the family Fabacea with a genome size of $738.09 \mathrm{Mbp}$ (Varshney et al., 2013). Southwest Asia and the Mediterranean region (especially Southeast Turkey and Syria) are considered as its primary centres of origin (Singh et al., 1997). Ethiopia is considered as one of the centres of secondary diversity for chickpea (van der Maesen, 1987). In Ethiopia, chickpea is the third largest food legume crop in area and production (CSA, 2015).

There are two types of chickpea depending on seed colour, shape, and size.
The Kabuli type has large, round or ram head and cream-colored seeds, and is grown in temperate regions. The Desi type chickpea is grown in the semi-arid tropics (Muehlbauer and Singh, 1987), and is characterized by relatively small angular shaped seeds with light brown, yellowish or black colour.

Ethiopia has a large number of Desi type chickpea landraces cultivated by farmers through traditional method of selection over centuries. These landraces have high capacity to tolerate biotic and abiotic stress; resulting in high yield stability under low input agricultural systems (Zeven, 1998). Thus, characterization of landraces and 
knowledge on the pattern of variation for important morpho-agronomic traits is needed for a proper management and a better exploitation of this gene pool (Jain et al., 1975; Gebrekidane, 1982; Assefa 2003).

The existence of genetic diversity has special significance for the maintenance and enhancement of productivity in agricultural crops in a country like Ethiopia, which is characterized by highly varied agro-climates and diverse growing conditions (Worede, 1993; Worede et al., 2000; Brush 2000). The Ethiopian landraces have tremendous genetic diversity in both domesticated and wild relatives (Edwards, 1991). The extent and pattern of genetic diversity in Ethiopian landraces is not yet systematically studied (Hailu et al., 1991).

Geographical separation with physical barriers and genetic barriers to cross ability is believed to give rise to genetic diversity among genetic materials (Singh, 2001). However, whether differences in geographic origin necessarily imply genetic distance in parental selection for hybridization is still a matter of some controversy. Joshi and Dhawan (1966) suggested the concept that geographic diversity may serve as an index of genetic diversity in parental selection. Others argue that genetic divergence was not apparently related to geographic diversity in some crops (Durga et al., 1985; Nadaf et al., 1986; Katule et al., 1992). If the former holds true, it is logical to expect that the physical barriers might have resulted in distinct genetic diversity of chickpea accessions growing in different parts of Ethiopia. Thus, the Ethiopian Biodiversity Institute (EBI), Debre Zeit Agricultural Research Centre (DZARC) and ICRISAT collected 202 new landraces from different areas of the country. Phenotypic characterization of these landrace collections is essential for their utilization in breeding programs for the improvement of the crop, and for gene bank curators for efficient and effective management of the collections. Therefore, the objectives of this experiment were to evaluate the genetic diversity among the Ethiopian chickpea landraces, the relative contribution of various morpho-agronomic traits to the total diversity in the associations and to study the association of geographic origin with genetic diversity.

\section{MATERIALS AND METHODS}

\section{Description of Study Areas}

The experiment was executed under rain fed condition at Sirinka and Jari. The former one is located at 110 45' North latitude and 390 36' 36" East longitudes. The altitude of Sirinka is 1850 meter above sea level in North Wollo Zone. The annual rainfall of this site is $1006.3 \mathrm{~mm}$ with $13.60 \mathrm{c}$ minimum and $26.70 \mathrm{c}$ maximum temperature. The second site, Jari, is located at 110 21' North latitude and 390 $47^{\prime}$ East longitudes and at an altitude of 1680 meter above sea level in South Wollo Zone. The annual rainfall of this site is $987.3 \mathrm{~mm}$ with $14.20 \mathrm{c}$ minimum and 28.70c maximum temperature. According to Sirinka Agricultural Research Centre soil classification (unpublished), the soils of the sites are classified as Vertisols.

\section{Experimental Materials}

In general 202 Desi type chickpea landrace collections from Amhara, Oromiya and Southern Nations, Nationalities and Peoples' Regional States were used for this study with two released varieties as checks, Fetenech (early maturing, 78 - 90 days to mature) and Minjar (high yielder, 2.2 5tons and recommended for this tested area). The landraces were collected from elevations ranging from 1174 to 2660 meter above sea level. The collections were made in 2013 (42) and in 2016 (160). Generally, 90 landraces were collected from 
Amhara region and 91 and 24 landraces were collected from Oromiya and Southern Nations, Nationalities and Peoples' Region, respectively. These landraces with two released varieties as checks were tested and characterized for agro-morphological traits.

\section{Experimental Design and Trial Management}

The experiment was planted on 02 September 2016 by using alpha lattice design with three replications at Sirinka and Jari under rain fed conditions. Each landrace was sown in two rows at $60 \mathrm{~cm}$, $30 \mathrm{~cm}$, and $10 \mathrm{~cm}$ spacing between plots, rows, and plants, respectively; with $1 \mathrm{~m}$ row length. All agronomic practices were done uniformly for all accessions as required. There was no fertilizer application.

\section{Data Collection}

The data of morphological, phenological, and agronomical traits were collected during the growth period of the crop, depending on the descriptors for chickpea (IBPGR, ICRISAT and ICARDA, 1993).

\section{Morphological Data}

1. Seed Coat Colour: It was scored visually sample of accession after threshing and winnowing and classified as black, dark brown, brown, light brown, ivory white, green and light yellow.

2. Seed Shape: It was scored visually sample of accession based on the descriptors and classifying as angular (ram's head), irregular rounded (owl's head) and pea shaped (smooth round).

3. Seed Testa Texture: It was scored visually sample of accession based on the descriptors and classifying by given a scale 3 for rough, 5 for smooth and 7 for tuberculated testa textures.

4. Flower Colour: This parameter was taken visually. The data was categorized using scale like 3 - when the flower colour was dark pink, 4 when the flower colour was light pink and 6 - when it was white (IBPGR, ICRISAT and ICARDA, 1993).

5. Stem Colour: It was taken visually during the peak growth stage and classified based on descriptors. A scale gave 1 up to 5 , we gave 1 - when the stem was light green, 2 - when the stem was green (dark green), 3 - when the colour was partly purple, 4 - when the colour was predominantly purple and 5 - when the stem colour was highly purple (IBPGR, ICRISAT and ICARDA Rome, 1993).

\section{Phenological Data}

1. Days to $50 \%$ pod setting: Number of days taken from emergence to time when $50 \%$ of plants in the plot produced at least one pod.

2. Pod Filling Period: Number of days from $50 \%$ flowering to the time when $75 \%$ the plants in the plot was physiologically matured.

3. Days to $75 \%$ Maturity: Number of days from emergence to the time when $75 \%$ of the plants in the plot reached $75 \%$ physiological maturity.

\section{Agronomical Data}

1. Number of Primary Branches: The total number of branches originating from the main stem and giving rise to secondary branches was counted at $75 \%$ physiological maturity.

2. Number of Secondary Branches: The total number of branches which arise from the primary branches was counted at $75 \%$ physiological maturity.

3. Pod Length: It was taken at maturity from five plants, one pod for each, by measuring pods by using a ruler and the length grouped as 3 when the pod is short ( $<15 \mathrm{~mm}), 5$ for medium (15 $-20 \mathrm{~mm}$ ) and 7 for long (>20 mm). 
4. Number of Pods per Plant: The total number of pods per plant was counted at physiological maturity.

5. Number of Seeds per Pod: The total number of seeds per pod was counted at physiological maturity from five plants one pod for each.

6. Plant Height: The plant height was measured on the main stem starting from the ground level to the tip of the plant using a ruler at $75 \%$ physiological maturity.

7. Diseases (Root rot and Fusarium wilt) damage score (1-9): this data scored 1 $9 ; 1=$ no infection (resistant); 3 for $1 \%$ plants infected (moderately resistant); 5 for $2-5 \%$ of plants infected (average reaction); 7 for $6-10 \%$ plants infected (moderately susceptible); 9 for more than $10 \%$ of plant in a plot affected (highly susceptible), (IBPGR, ICRISAT and ICARDA Rome, 1993).

8. Total Biomass: The total weight of above ground biomass was taken by using electronic sensitive balance for each plot.

9. Hundred Seed Weight: Hundred seeds was counted and weighed by using electronic sensitive balance for each material in three replications.

10. Seed Yield: This parameter was taken after harvesting, threshing and winnowing. The seed yield was weighed by using electronic sensitive balance for each plot.

11. Harvest Index: It was calculated as the ratio of seed yield to biomass yield in percent.

\section{Data Analysis}

\section{Analysis of Variance}

ANOVA was performed using SAS (SAS, 2004) as per the following linear model for alpha lattice design: $\mathrm{Yijk}=\mu+\mathrm{Ri}$ $+\mathrm{Bij}+\mathrm{Tk}+$ eijk: Where, $\mu=$ the grand mean of trait $\mathrm{Y} ; \mathrm{Ri}=$ the effect of Replicate I;
Bij= effect of Block $\mathrm{j}$ within Replicate I; $\mathrm{Tk}=$ Effect of treatment $\mathrm{k}$.

\section{Cluster Analysis}

Cluster analysis is important to group genotypes in to homogeneous sets based on their response to the environments considered. Elements within the same group or cluster are relatively homogeneous and elements in different clusters are relatively heterogeneous. The clustering was done using proc cluster of SAS and the average linkage option was used. Genetic distance between clusters was calculated using the generalized Mahalanobis's D2 statistics. The D2 is defined as:

D2ij $=\left(\bar{X}_{i-} \bar{X}_{j) 1}\left(\bar{X}_{i-} \bar{X}_{j}\right) ;\right.$ Where $\mathrm{D} 2 \mathrm{ij}=$ the distance between any two groups $i$ and $j ; \bar{X}_{i \text { and }} \bar{X}_{j}$ the vector mean of the traits for the ith and jth groups respectively.

\section{Analysis of Qualitative Data}

Frequency distribution of the various categories of qualitative traits was studied in to the zones and altitude from which the accessions were collected. The ShannonWeaver diversity index $\left(\mathrm{H}^{\prime}\right)$ was computed using the phenotypic frequencies to assess the overall phenotypic diversity for each character by zones and altitude ranges. The altitude was arbitrarily classified in to three altitude classes, <1801, 1801 - 2200, and $>2200$ masl. The Shannon-Weaver diversity index as described by Hutchenson (1970) was used to calculate phenotypic diversity for $\mathrm{jth}$ trait with $\mathrm{n}$ sub classes:

$$
\mathrm{H}=\sum_{i=1}^{n}
$$
number of classes of each qualitative trait, $i$ is the jth class of a character and Pi is the proportion of ith class in a character; $\ln$ is the natural logarithm symbol. 


\section{RESULTS AND DISCUSSION}

Analysis of variance revealed highly significant differences $(\mathrm{P}<0.001)$ among the genotypes for most of the studied traits except number of seeds per pod at both locations (Table 1). This indicates that there was adequate genetic variability among the genotypes for most of the traits at both locations. However, pooled differences among the genotypes were non-significant. Similarly, previous studies on chickpea landraces indicated significant variations for most of the traits like plant height, days to flowering, days to maturity, number of pods per plant, hundred seed weight and grain yield (Tesfamickael et al., 2014; Uday et al., 2012).

Table 1: Mean Squares and CV\% of Morpho-Agronomic Characters of Chickpea Accessions.

\begin{tabular}{llll}
\hline Traits & & \multicolumn{3}{c}{ Mean square $(\mathrm{CV} \%)$} \\
& Sirinka & Jari & Combined \\
\hline DF & $24.25^{* *}(6.56)$ & $25.83^{* *}(5.04)$ & $4.24^{\mathrm{ns}}(8.2)$ \\
DP & $31.23^{* *}(6.46)$ & $15.06^{* *}(4.89)$ & $9.73^{\mathrm{ns}}(4.98)$ \\
PFP & $18.70^{* *}(6.07)$ & $34.74^{* *}(5.02)$ & $5.99^{\mathrm{ns}}(6.23)$ \\
DM & $42.32^{* *(4.28)}$ & $22.08^{* *}(5.68)$ & $5.39^{\mathrm{ns}}(4.52)$ \\
CW & $38.83^{* *}(8.15)$ & $132.25^{* *}(11.5)$ & $14.03^{*}(22.31)$ \\
NLtL & $0.87 * *(5.97)$ & $3.08^{*}(15.78)$ & $0.79^{*}(16.23)$ \\
PH & $31.12^{* *}(9.85)$ & $86.37^{* *}(17.60)$ & $8.61^{* *}(20.13)$ \\
PB & $0.72^{* *}(19.65)$ & $0.05^{\mathrm{ns}}(21.5)$ & $0.11^{\mathrm{ns}}(28.9)$ \\
SB & $11.11^{* *}(17.16)$ & $0.92^{\mathrm{ns}}(20.42)$ & $1.88^{*}(25.61)$ \\
NPP & $520.46^{* *}(21.02)$ & $167.32^{*}(28.6)$ & $50.90^{* *}(30.2)$ \\
NSP & $0.08^{\mathrm{ns}}(12.06)$ & $0.02^{\mathrm{ns}}(15.23)$ & $0.029^{\mathrm{ns}}(11.6)$ \\
PL & $0.24^{* *}(26.5)$ & $0.85^{*}(29.42)$ & $0.25^{*}(31.2)$ \\
HSW & $8.34^{* *}(13.23)$ & $5.27^{* *}(12.52)$ & $0.43^{\mathrm{ns}}(8.96)$ \\
GYKH & $441140.22^{* *}(28.66)$ & $193086.47 * *(24.56)$ & $23558.56^{\mathrm{ns}}(30.2)$ \\
BMKH & $1936174.5 * *(25.97)$ & $734469.2^{*}(29.62)$ & $123242.6^{\mathrm{ns}}(32.21)$ \\
HI & $240.00^{* *}(21.48)$ & $0.55^{\mathrm{ns}}(18.96)$ & $1.42^{\mathrm{ns}}(28.9)$ \\
\hline
\end{tabular}

$\mathrm{DF}=$ Days to flowering, $\mathrm{DP}=$ Days to pod setting, $\mathrm{PFP}=$ Pod filling period, $\mathrm{DM}=$ Days to maturity, $\mathrm{CW}=$ Canopy width, $\mathrm{NLtL}=$ Number of leaflets per leaf, $\mathrm{PH}=$ Plant height, $\mathrm{PB}=$ Primary branches, $\mathrm{SB}=$ Secondary branches, NPP $=$ Number of pods per plant, NSP $=$ Number of seeds per pod, PL $=$ Pod length, $\mathrm{HSW}=$ Hundred seed weight, $\mathrm{GYKH}=$ Grain yield kilo gram per hectare, $\mathrm{BM}=$ Biomass kilo gram per hectare, $\mathrm{HI}=$ Harvest index, ${ }^{\mathrm{ns}}=$ non - significant and $*,{ }^{*}$ significant at $5 \%$ and $1 \%$ probability level, respectively.

Clustering of genotypes was performed using 16 traits that were significantly different among the accessions. Clustering was done based on average linkage method using SAS software. The pseudo F- statistic and the pseudo $t^{2}$ statistic were examined to decide the number of clusters (SAS, 2004). This suggested that about 5 clusters would be an appropriate classification for the 204 chickpea genotypes. The accessions were grouped into five diversity classes (Table 2), different members within a cluster being assumed to be more closely related with each other than those members in the other clusters in terms of the traits under consideration. Similarly, accessions in clusters with non-significant distance were assumed to have more close relationships with each other than they are with those in significantly distant clusters. The cluster grouping is given the dendrogram which is depicted in Figure 1.

Cluster I was the largest with 96 accessions or constituting closer to $47 \%$ of the total population, followed by cluster II with 68 accessions or $33 \%$ of the total 
population. These two clusters (I and II) comprised accessions with low yielding potential, larger seed size and early maturity. Cluster III constituted $36(17 \%)$ accessions while cluster IV and cluster $\mathrm{V}$ had 3 and 1 accessions; respectively. Cluster V consisted of solitary genotype, entry 118 (Acc. IE-16-118). Accession IE16- 118 had the unique nature of having the highest values of secondary branches, grain yield and biomass yield than all accessions in the other clusters.

The frequency of accessions collected from the different zones in a specific cluster is given in Table 3. This was done to see if accessions from one region group into the same cluster. The result showed that, even though the clusters contained accessions from different regions, accessions from three zones, namely North Gonder, North Shewa and East Shewa, were highly represented in clusters I, II, and III with a total number of $(10,27$ and 21), (18, 10 and 4) and (26, 7 and 3) accessions; respectively (Table 2 ).

The pair wise generalized square distance $\left(D^{2}\right)$ among the five clusters is presented in Table 4. The maximum distance was found between clusters IV and $\mathrm{I}\left(\mathrm{D}^{2}=82.38\right)$. The second most divergent clusters were cluster $\mathrm{V}$ and $\mathrm{I}\left(\mathrm{D}^{2}\right.$ $=67.18)$, and the third divergent clusters were cluster $\mathrm{V}$ and IV $\left(\mathrm{D}^{2}=53.94\right)$. The genetic divergence between clusters $\mathrm{V}$ and III ( $\left.\mathrm{D}^{2}=37.91\right), \mathrm{V}$ and II $\left(\mathrm{D}^{2}=42.02\right), \mathrm{IV}$ and II $\left(\mathrm{D}^{2}=41.39\right)$, III and I $\left(\mathrm{D}^{2}=32.39\right)$ were also highly significant $(\mathrm{P}<0.001)$. According to Chandel and Joshi (1983), populations from areas distantly separated geographically and having complex environments is expected to accumulate large genetic diversity. In this study, some accessions from the same region were scattered over different clusters, indicating that genetic diversity in chickpea is not uniformly distributed over the regions. Accessions from North Gonder and West Shewa were distributed in four clusters out of five with irregular pattern. The distances between accessions from North Gonder (IV and I, IV and II, and III and I); from West Shewa (V and I, V and II, V and III, and III and I) were highly significant. This implies that crosses between parents selected from these pairs of clusters are expected to result in good level of genetic recombination and generate desirable segregants with broad genetic base.

The minimum and maximum distances between pairs of clusters shown in Table 2 are 8.44 (between clusters I and II) and 82.38 (between clusters I and IV). Maximum genetic recombination and variation in the subsequent generation is expected from crosses that involve parents from the clusters characterized by maximum distances between them. There was non-significant distance between cluster I and II $\left(\mathrm{D}^{2}=8.44\right)$ and cluster II and III $\left(\mathrm{D}^{2}=8.77\right)$, suggesting close relationship among the accessions.

Table 2. Distance Matrix for 5 Clusters formed by 204 Chickpea Genotypes

\begin{tabular}{llllll}
\hline Clusters & I & II & III & IV & V \\
\hline I & 0 & 8.44499 & $32.93084^{* *}$ & $82.37948^{* * *}$ & $67.17946^{* * *}$ \\
II & & 0 & 8.77427 & $41.39001^{* * *}$ & $42.02385^{* * *}$ \\
III & & & 0 & 15.24779 & $37.91786^{* * *}$ \\
IV & & & & 0 & $53.94062^{* * *}$ \\
V & & & & 0 \\
\hline
\end{tabular}

Generally, clustering has exposed similarities of accessions collected from adjacent zones and dissimilarities of accessions collected from regions geographically located apart. This may indicate that more frequent exchange of 
chickpea genotypes between adjacent zones than between regions very far from. However, some accessions did not follow that pattern, which may witness the fact that genotypes could be shared among regions very far apart. For example, three genotypes from East Shewa were grouped in cluster III with accessions from North Gonder. It is also worthy to note that cluster II contained $39.7 \%$ of the accessions from North Gonder were classified with accessions from Gurage zone which is far from North Gonder. The North Gonder accessions were also scattered in four clusters; I, II, III, and IV.

The same is true for the few accessions representing zones such as West Shewa, North Shewa and Gurage. This might witness the fact that some genotypes are scattered over large ecological zones, which could be due to exchange of genetic material over larger distances. Generally, the clustering did not show clear pattern of grouping based on geography or physical distances.

Crossing of best accessions from distant clusters is expected to produce transgressive segregants which exceed both parents (Gemechu et al., 2003). Hence, maximum variation in the subsequent generations is expected from crosses that involve parents from the clusters characterized by maximum inter-class distances. For example crossing genotype 118 of cluster $\mathrm{V}$ with genotype such as 19 , $24,26,27,55,109,158$, and 181 of cluster III is expected to produce interesting segregants. Crossing entry 60 in cluster IV with those in cluster II (entry 1 and 35) is also expected to give high yielding crosses. 


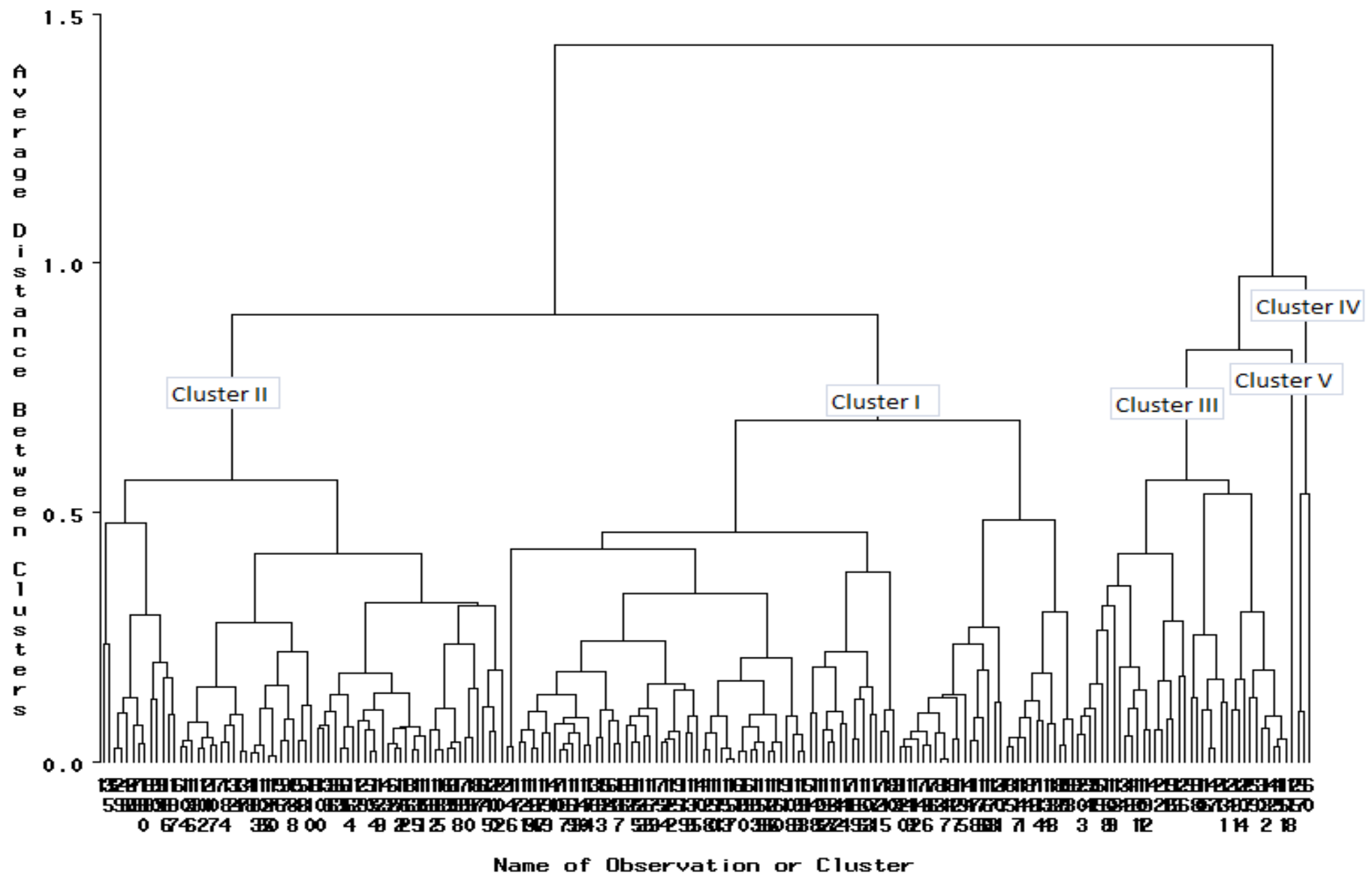

Figure 1. The Dendrogram of the distribution of 204 chickpea genotypes into five clusters. 
Qualitative traits are less influenced by environmental factors unlike quantitative traits (Singh et al., 2008). Qualitative morphological traits of chickpea that were considered in this study include growth habit, stem colour, seed coat colour, seed shape, seed testate texture, pod dehiscence, flower colour, and leaf type. From the traits studied, only growth habit, stem colour, and seed coat colour showed wide differences among genotypes while the other traits like pod dehiscence, flower colour, seed shape, seed testa texture and leaf type were monomorphic. Five types of growth habit were observed; namely erect, semi erect, semi- spreading, spreading and prostrate. Semi spreading $(46 \%)$ was the most predominant among the genotypes, followed by spreading (35.8\%) and prostrate $(11.3 \%)$, while the semi - erect and erect types were the least frequent $(5.9 \%)$ and $(1 \%)$, respectively.

Genotypes varied for stem colour and showed four types of colour categories. The majority of genotypes had predominantly purple stem colour $(48.0 \%)$ followed by partly purple $(35.3 \%)$ and highly purple $(11.8 \%)$, while the minimum frequency was observed for the dark green type $(4.9 \%)$.

The studied genotypes showed substantial differences for seed coat colour, which had10 different categories. The maximum frequency was recorded for light brown $(59.8 \%)$ followed by brown $(26.0 \%)$, green light yellow $(9.8 .0 \%)$, while light brown with black, brown with black, yellow with black and green light yellow with black occurred with the least frequency $(4.4 \%)$.

In addition to the morphological traits, the responses of the accessions to the diseases root rot and fusarium wilt, and to the insect pest pod borer were scored. The accession varied significantly for their response to these biotic factors. For root rot, 184 of the 204 genotypes (90.1\%) scored 1 or resistant, two genotypes (1\%) scored 3 or moderately resistant, three genotypes $(1.5 \%)$ scored 5or average reaction, 13 genotypes $(6.4 \%)$ scored 7 or moderately susceptible, and two genotypes $(1 \%)$ scored 9 or highly susceptible

Fusarium wilt was another disease which scored in this study. According to the observation, 123genotypes (60.3\%) scored 1 or resistant, 11 genotypes $(5.4 \%)$ scored 5 or average reaction, 16 genotypes $(7.8 \%)$ scored 7or moderately susceptible and 54 genotypes $(26.5 \%)$ scored 9 or highly susceptible.

Pod borer is a noxious pest of chickpea causing heavy damage to the crop. It damages almost all the pods in case of severe damage, but causes nearly 20-30\% annual yield losses in Ethiopia (ICRISAT, 2012). This study also assessed the response of the genotypes to this noxious pest. The result showed that, 61 genotypes $(29.9 \%)$ scored 1 or resistant, 18 genotypes $(8.8 \%)$ scored 3 or moderately resistant, 66 genotypes $(32.4 \%)$ scored 5 or average reaction, 21 genotypes $(10.3 \%)$ scored 7 or moderately susceptible, and 38 genotypes $(18.6 \%)$ scored 9 or highly susceptible to this pest.

\section{Estimates of Diversity for Each Zones Depending on Qualitative Traits}

The Shannon-Weaver diversity index was calculated to compare phenotypic diversity index $(\mathrm{H})$ among characters and groups. Table 5 shows the estimates of ShannonWeaver diversity index for 8 discrete characters by zones. This index was previously used to determine the range of variation in several crop species including wheat (Jain et al., 1975; Getachew et al., 1997), barley (Fassil et al., 2001) and finger millet (Dagnachew et al., 2012). 
Table 3. Estimates of the Shannon-Weaver Diversity Index (H), for 8 Qualitative Traits and 7 Zones

\begin{tabular}{llllllllll}
\hline Zones & GH & SC & SCC & SSh & STT & RRR & FWR & PB & Mean H \pm SE \\
\hline East Gojam & 0.64 & 0.64 & 1.1 & 0 & 0 & 0 & 1.1 & 1.1 & $0.57 \pm 0.07$ \\
East Shewa & 1.14 & 0.92 & 0.46 & 0 & 0 & 0.52 & 0.72 & 1.34 & $0.64 \pm 0.06$ \\
Gurage & 1.36 & 1.15 & 1.02 & 0 & 0 & 0.46 & 1.05 & 1.45 & $0.81 \pm 0.08$ \\
North Gonder & 1.14 & 0.85 & 1 & 0.08 & 0.08 & 0.2 & 0.92 & 1.47 & $0.72 \pm 0.07$ \\
North Shewa & 0.94 & 0.79 & 1.04 & 0 & 0 & 0.38 & 0.93 & 1.48 & $0.70 \pm 0.05$ \\
South West Shewa & 0.47 & 0.99 & 4.42 & 0 & 0 & 0.6 & 4.02 & 5.72 & $2.03 \pm 0.05$ \\
West Shewa & 1.06 & 1.13 & 0.76 & 0 & 0 & 0.46 & 1.06 & 1.34 & $0.73 \pm 0.04$ \\
Over all & 0.96 & 0.92 & 1.40 & 0.01 & 0.01 & 0.37 & 1.40 & 1.99 & $0.88 \pm 0.06$ \\
\hline
\end{tabular}

$\mathrm{GH}=$ growth habit, $\mathrm{SC}=$ stem colour, $\mathrm{SCC}=$ seed coat colour, $\mathrm{SSh}=$ seed shape, $\mathrm{STT}=$ seed testa texture, $\mathrm{RRR}=$ root rot response, FWR= Fusarium wilt response, $\mathrm{PB}=$ Pod Borer and $\mathrm{SE}=$ standard error of the mean.

Over all, all characters revealed diversity ranging from 0.37 for root rot to 1.99 for pod borer response. Monomorphism $(\mathrm{H}<$ 0.10) was observed in all accession collected from all Zones for the traits seed shape and testa texture (Table 7).The highest diversity indices pooled over characters within zones were recorded for accessions from South West Shewa $(\mathrm{H}=$ $2.03 \pm 0.05)$ followed by Gurage $(\mathrm{H}=0.81$ \pm 0.08), West Shewa $(\mathrm{H}=0.73 \pm 0.04)$, North Gonder $(\mathrm{H}=0.72 \pm 0.05)$, and North Shewa $(\mathrm{H}=0.70 \pm 0.05)$ whereas genotypes from East Gojam showed relatively lower diversity estimates of $(\mathrm{H}=0.57 \pm 0.07)$

\section{Cluster Analysis Based on Qualitative Traits}

The 204 chickpea genotypes were clustered into five distinct groups based on eight qualitative traits. The traits used for clustering were growth habit, stem colour, seed coat colour, seed shape, seed testa texture, root rot response, Fusarium wilt response, and pod borer response. The number of genotypes belonging to each cluster varied from one in cluster $\mathrm{V}$ to 111 in cluster I.
The largest cluster (Cluster I) included chickpea genotypes with all types of growth habits except erect type, and all stem colour types except light green. The genotypes in this cluster have angular seed shape with rough texture. Almost all genotypes (99\%) in this cluster are totally free from Fusarium wilt and root rot diseases. Compared to others clusters, the genotypes in cluster I had better response to pod bore; $43.2 \%$ of the genotypes in this cluster being free this pest.

Cluster II comprised 77 genotypes $(37.8 \%)$ and have four types of growth habit namely; semi- spreading, spreading, prostrate and semi-erect. The genotypes in this cluster have predominantly purple stem colour (52\% of the genotypes), followed by partly purple stem colour $(29.9 \%)$. Most of the genotypes in cluster II have light brown seed coat colour $(64.9 \%)$, and $20.8 \%, 10.4 \%, 3.9 \%$ and $1.3 \%$ of the genotypes have brown, green light yellow, brown with black, and yellow with black seed coat colour, respectively. All genotypes in this cluster have angular seed shape, except one genotype, with rough testa texture. Genotypes in this cluster are the most susceptible to Fusarium wilt (63.6\% highly susceptible, $18.2 \%$ susceptible and $18.9 \%$ average reaction); while $96.1 \%$ and $15.6 \%$ of the genotypes are free from root rot and pod borer, respectively. 
Cluster III consisted of 10 genotypes $(4.9 \%)$ with four types of growth habits andpod borer, respectively.

Cluster III consisted of 10 genotypes $(4.9 \%)$ with four types of growth habits and stem colour. Their seed coat colour is light brown, brown and green light yellow with angular shape and rough texture. 50\% and $40 \%$ of the genotypes in cluster III have brown and light brown seed colour, respectively. All genotypes in this cluster were from Fusarium wilt, but were highly susceptible to root rot $(80 \%$ susceptible and $10 \%$ highly susceptible).

Cluster IV consisted of five genotypes (2.5\% of all genotypes) that have semi spreading, spreading and prostrate types of growth habits. Most of the genotypes have predominantly purple stem colour $(80 \%)$ and light brown seed coat colour $(60 \%)$. All genotypes were susceptible to root rot and Fusarium wilt with average reaction to pod borer.

Cluster V is the solitary group, it consisted only one genotype. This genotype has semi spreading growth habit and highly purple stem colour. Its seed shape and testa texture is angular and rough, respectively. Diseases and insect pest response of this genotype was relatively the same as the genotypes in cluster IV. In the quantitative cluster, the solitary cluster $\mathrm{V}$ consisted entry 118 (accession IE-16- 118), which had the tallest plant height, the highest number of secondary branches, highest grain yield and biomass, and relatively late maturity than the other clusters.

\section{SUMMARY AND CONCLUSION}

Analysis of variance revealed highly significant differences among the accessions for most of the studied traits except number of seeds per pod at both locations. This indicates that there was adequate genetic variability among the accessions for most of the traits. The accessions clustered into five distinct groups of different sizes based on quantitative traits. The clustering pattern indicated that the number of accessions in each cluster varied from 1 in cluster $\mathrm{V}$ and 96 in cluster I. This indicates there is high genetic diversity in the Ethiopian chickpea landraces even though it was not uniformly distributed across the regions. The existence of wider agro-morphological diversity among the chickpea collections implies the potential to improve the crop and the need to conserve the diversity. Accessions from different regions of origin might be closely related regardless of their geographic origin and accessions from the same regions of origin also might have different genetic background. There was no definite correspondence between geographic origin and genetic diversity. Parental selection should, therefore, not be based on geographic difference but it should rather be made based on systematic assessment of genetic distance in a specific population. Future collecting operations of chickpea germplasm should strategically focus on areas with relatively large variation. From genetic conservation point of view, it appears that South West Shewa, Gurage, West Shewa and North Gonder, with appropriate altitudinal focus, could be suitable as in situ conservation sites.

\section{ACKNOWLEDGEMENTS}

First of all, the authors' deepest gratitude and acknowledge goes to Amhaera Agricultural Research Institute and Sirinka Agricultural Research Centre for providing research budget and facilitate the process. We would like also to express sincere thanks to Sirinka Agricultural Research Centre pulse case team members for contributing their great effort this successful accomplishment of the experiment. 


\section{REFERENCES}

Assefa, A. 2003. Genetic variability and Breeding Potential of Barley (Hordeum vulgare L.) Landraces from North Shewa in Ethiopia. PhD Thesis, Faculty of natural and Agricultural Sciences University of Free State, Bloemfontein, South Africa. 226 p.

Brush, S. B. 2000. The issue of in situ conservation of crop genetic resources. Genes in the field: on farm conservation of crop diversity/edited by Stephen B. Brush. IBBNO- 88936- 884-8 International Development Research centre.

Central Statistical Authority 2014/2015. Agricultural Sample Survey, Volume I: Report on Area and Production for major crops (Meher Season) Statistical Bulletin No. 578 Addis Ababa, Ethiopia

Chandel, K. P. and Joshi B. S. 1983. Multivariate analysis in green seeded pea Indian J. Agric. Sci., 53(4): 198 - 200.

Dagnachew Lule1, Kassahun Tesfaye and Masresha Fetene 2012. Qualitative traits diversity and eco-geographical distribution in finger millet (Eleusine coracana GURE subsp. Coracana) landraces from eastern and south eastern Africa: An implication for germplasm collection and conservation African Journal of Plant Science Vol. 6(13), pp. 346-354, October 2012 Academic Journals

Durga Prasad M. M. K., Arunachachalam V. and Bandy opadyay A. 1985. Diversity pattern elucidating parents for hybridization in varieties of groundnut. Arachis hypogaea L., Trop. Agric. 62:237 - 242 .

Edwards, S. B. 1991. Crops with wild relatives found in Ethiopia. In: Engels J.M.M., Hawkes J.G. and Worede Melaku (Eds.), Plant genetic resources of Ethiopia. Cambridge University Press pp. 42-74.

Fassil Kebebew, Yemane Tsehaye and T. McNeilly. 2001. Morphological and farmers cognitive diversity of barley (Hordeum vulgare L. [Poaceae]) at Bale and North Shewa of Ethiopia. Genetic resources and crop evolution, 48:1-10.

Gebrekidane, B. 1982. Utilization of sorghum germplasm in sorghum improvement: Sorghum in the eighties. p. 335-345. In Proc. of the international symposium on sorghum, January 2-7, 1981. Pantanchiru, A.P. India. ICRISAT.

Getachew Belay, Ephrem Bechere, D. Mitiku, A. Merker and S. Tsegaye. 1997. Patterns of morphologigal diversity in tetraploid wheat (Triticum turgidum L.) landraces from Ethiopia. Acta Agric. Scand., Sect. B. Soil and Plant Sci. 47:221-228.

Hailu Mekibeb, Abebe Demissie and Abebe Tullu 1991. Pulse crops of Ethiopia. In: Engels J.M.M., Hawkes J.G. and Melaku Worede (Eds), Plant genetic resources of Ethiopia, Cambridge University Press, pp. 328 343.

Hutchenson, K. 1970. A test for comparing diversities based on the Shannon formula. Journal of Theoretical Biology, 29:151-154.

IBPGR, ICRISAT and ICARDA. 1993. Descriptor for chickpea (Cicer arietinum L.). International Board for Plant Genetic Resources, Italy; International Crop Research Institute for the SemiArid Tropics, Patancheru, India and International Centre for Agricultural Research in Dry Areas, Aleppo, Syria.

Jain, S.K., C.O. Qualset, G.M. Bhatt, and K. K. Wu. 1975. Geographical pattern of phenotypic diversity in a world collection of durum wheat. Crop Science, 15: 700-704.

Joshi A.B. and Dhawan N.L. 1966. Genetic improvement in yield with special reference to self-fertilizing crops. India

Katule B.K., Thombare M. V., Dumbre A.D. and Pawar B.B. 1992. Genetic diversity in bunch groundnut. J. of 
Maharashtra Agric. Universities 17: $302-$ 303.

Muehlbauer, F. J. and Singh, K. B. 1987. Genetics of chickpea, In: Saxena M. C. and Singh K.B. (eds.): the chickpea. CAB International. p. 99/125.

Nadaf H.L., Habia A.F. and Groud J. V. 1986. Analysis of diversity in bunch groundnut. J. Oilseeds res. 3: 37-45

SAS Institute 2004 SAS/STAT guide for personal computers, version 9.0 edition, SAS Institute Inc. Cary, NC.

Singh, R.K and Chaudhary. 1977. Biometrical methods in quantitative genetic analysis. Kalyani Publisher, New Delhi, Ludhiana, India. 300 p.

Singh BD 2001. Plant Breeding: Principles and methods. Kalyani Publishers, New Delhi. pp. 896

Tesfamichael Semere, Stephen Githiri, Aggrey Bernard, Ganga Rao, Damaris Achieng, Abhishek Rathore and Anil Kumars, 2014. Assessment of genetic variation and heritability of agronomic traits in chickpea (Cicer arietinum L). International Journal of Agronomy and Agricultural Research, 5 (4): 76-88.

Uday Chand Jha1, Singh D.P. and Roopa Lavanya 2012. Assessment of genetic variability and correlation of important yield related traits in chickpea (Cicer arietinum L.) Department of Genetics and Plant Breeding G.B. Pant University of Agriculture \& Technology, Pantnagar-263145 India agricultural research communication centre wnw.arcjournals.com/ indianjournals.com Legume Res., 35 (4): 341 - 344, 2012.
Worede, M., 1993. The role of Ethiopian farmers in the conservation and Utilization of crop genetic resources. In: International crop science society of America, D. R. Buxton et al (Eds.). Madison, WI: Crop science society of America.

Worede, M., T. Tesemma and R. Feyissa. 2000. Keeping diversity alive: an Ethiopian perspective. In Stephen B. Brush. (Eds.) Genes in the field: on farm conservation of crop diversity. IBBNO88936- 884-8.International Development Research Centre.

Van der Maesen, L.J.G. 1987. Origin, history and taxonomy of chickpea. In: Saxena MC, Singh KB (Eds). The Chickpea. Wallingford: C.A.B International, pp. 11-34.

Varshney R. K., Song C., Saxena R. K., Azam S., Yu S., Sharpe A. G., et al. . 2013. Draft genome sequence of chickpea (Cicer arietinum) provides a resource for trait improvement. Nat. Biotechnol. 31, 240-246. 10.1038/nbt.2491.

Zeven AC 1998. Landraces: A review of definitions and classifications. Euphytica, 104(2):127-139. 